Fecha de recepción: noviembre 2012

Fecha de aceptación: mayo 2013

Versión final: junio 2014

\section{De New York a Buenos Aires y del Hip Hop a la Cumbia Villera El protagonismo de la imagen en los procesos de transculturación}

Leandro Allochis *

Resumen: En tanto que las imágenes portan simbologías e ideologías y que la industria cultural ha usado profusamente esta cualidad emulativa y persuasiva, nos ocuparemos sobre los modos en que, dentro del contexto actual de las comunicaciones globales, las representaciones trascienden como nunca antes sus territorios y grupos culturales de origen. Mediante un caso de análisis identificaremos los alcances y efectos de la fotografía en la propagación-apropiación-hibridación entre culturas territoriales lejanas. Una revisión sobre el funcionamiento particular de los mensajes visuales en el contexto de las comunicaciones globales, donde su potenciado nivel simbólico y capacidad evocativa de prototipos culturales, ha complejizado su función de representar, a la de evocar y significar culturalmente, más allá de sus cualidades y proposiciones de origen.

Palabras clave: cultura - cumbia villera - discurso visual - Fotografía - globalización - hip hop - iconografía - imaginario social - indumentaria - moda - representación - semiótica - territorio.

[Resúmenes en inglés y portugués en la página 35]

${ }^{(*)}$ Profesor de Artes Visuales . Fotógrafo conceptual y artista visual . Formación en las disciplinas de Iconografía y Simbología del Arte (Universidad de Sevilla), Historia de la Moda (Instituto Andaluz de Teatro), Sociología del Arte (UBA) y Semiótica del Arte (IUNA). Docente del Museo Nacional de Bellas Artes de Buenos Aires y de la Facultad de Diseño y Comunicación de la Universidad de Palermo. [Ver CV completo en página 205]

\title{
Introducción
}

Observamos dos tapas de disco musicales: una de Hip Hop estadounidense y otra de Cumbia Villera argentina. Los músicos de sexo masculino retratados en ambas portadas coinciden en su indumentaria y pose: actitud ruda y desafiante, ropa deportiva holgada, joyas brillantes y calzado ostentoso. Si el estilo musical, idioma, época de origen y nacionalidad de ambos álbumes son diferentes, nos plantearemos qué tipo de vinculaciones han operado entre ambas fotografías, para producir tal mímesis. De inmediato surge preguntar si la apropiación de una imagen conlleva la asimilación del imaginario que porta, si la 
imitación formal de repertorio visual hereda también su nivel simbólico e ideológico. Si esto fuera así, estaríamos en condiciones de otorgar a estas fotografías un carácter evocativo privilegiado.

Más allá de cuáles sean los alcances y consecuencias de este parentesco, queda claro que tales imágenes han logrado traspasar sus límites territoriales y culturales, convirtiéndose la fotografía y sus modos de circulación en un ágil soporte comunicativo y persuasivo en la era de la globalización. Se trata entonces de plantearnos que lo global altera los significados y funciones en el plano de la cultura y de la construcción de identidades y el papel que juegan las imágenes en este fenómeno (Samour, 2006).

Estas fotografías de músicos (mediante su circulación como mercancía de las industrias culturales) se inscriben dentro de los procesos de la construcción social del cuerpo humano, en vínculo con el establecimiento de estéticas y expresiones corporales (Sevilla, 2009) que permiten la producción de ofertas identificatorias y su consumo apropiativo en diferentes territorios. El análisis de las similitudes e hibridaciones estéticas entre las representaciones visuales de la cultura musical del Hip Hop estadounidense y la Cumbia Villera Argentina permitirá explicitar los mecanismos formales y simbólicos que los emparentan, para evidenciar el modo en que las prácticas de producción y reproducción simbólica del mundo mediante las imágenes, se encuentra traspasado por el fenómeno de lo global.

\section{Hip Hop y Cumbia Villera}

A los fines de este análisis conformamos un corpus seleccionando dos fotografías de portadas de álbumes musicales, puntualizando desde el principio que nuestro acercamiento a ellas será en su cualidad de signos icónicos o figurativos, donde más allá de reconocer ciertos motivos, antepondremos la idea de que están allí por otra cosa más que por sí mismas, es decir por las connotaciones que las acompañan. Un abordaje del funcionamiento de la imagen como signo, mediante un mensaje icónico portador de connotadores de diverso orden, como usos socioculturales de los objetos y de las posturas, citas y figuras retóricas (Joly, 2009).

Observemos entonces, por un lado la fotografía de portada del álbum Walk this way (Recop. 2010) del trío de música rap Run DMC (Queens, Nueva York), y por otro la portada del álbum Rompiendo el silencio (2006) de la banda de cumbia argentina Néstor en Bloque. En ambas imágenes los músicos visten ropa deportiva holgada, collares de cadenas plateadas y doradas muy gruesas con medallones y dijes, en una pose corporal desafiante y firme. Revisando un corpus más amplio de imágenes de ambos grupos musicales (posters, fotografías de actuaciones y promocionales) volvemos a encontrar similitudes en la elección de indumentaria deportiva, tamaños de prendas y joyas maximizados, presencia de texturas brillantes (nylon, vinilo, cuero, metal) y uso de accesorios y calzado con el logotipo de la marca deportiva, especialmente visible.

Antes de continuar con el análisis formal de las imágenes, será valioso enmarcar brevemente los escenarios socio-históricos que rodean a cada uno de estos grupos culturales, que nos permita incluir el contexto institucional de producción y recepción de la obra, como nivel pragmático que completa el análisis textual de la imagen (Joly, 2009). Nos 
acercaremos a estos datos desde una noción de origen geográfico entendida cada vez menos como espacio y escenario concreto y más como práctica; como lugar que adquiere sentido en tanto se lo experimenta como lugar practicado (De Certeau, 1996). Una descripción de la relación músicas/culturas juveniles donde el espacio (el cuerpo, la casa, la calle, la ciudad, el mundo, las autopistas de información) se forma en el conjunto de representaciones, símbolos y valores que provienen de ámbitos que no pueden contenerse en la idea de localización geográfica.

Para comenzar, puntualizaremos que la cultura del Hip Hop, surgida a fines de 1960 de las comunidades afroamericanas y latinoamericanas de los barrios populares neoyorquinos de Bronx, Queens y Brooklyn, enmarca una serie de expresiones culturales urbanas de protesta social, que incluyen expresiones artísticas como el graffiti, el breakdance y el rap. El Rap nació en la periferia urbana de Nueva York en la zona de South Bronx, donde las personas negras habían sido segregadas, junto con las latinas (la mayoría portorriqueñas). Asimismo en Los Ángeles (California) los barrios como Compton, Watts o South Central (donde nació el género Gangsta Rap a principios de los 90) también estaban habitados por afroamericanos, mexicanos y centroamericanos. El Hip Hop se convertirá así en el movimiento cultural dominante de las minorías que poblaban estas comunidades marginales, con composiciones musicales inspiradas en vivencias barriales y que denunciaban desigualdades sociales. La mayoría de los "raperos" conectan con la historia de la vida de Malcolm X, en la experiencia de sobrevivir en una sociedad injusta con la comunidad negra en Estados Unidos. Especialmente el grupo Public Enemy (1982) irrumpirá en la escena neoyorkina con un fuerte contenido político y letras que reflejaban la situación de la comunidad negra. (Castellanos, 2012). Si bien los orígenes del Hip Hop se remontan a la década de 1960, su imagen y sobre todo su música se volverá popular y trascenderá las fronteras del país a partir de 1980, donde los seguidores de esta corriente musical producirán un estilo estético particular, especialmente en la indumentaria masculina, con un evidente interés por la demostración de poder y opulencia, mediante el uso de joyería y prendas maximizadas de marcas reconocidas.

Por su parte la denominación Cumbia Villera surge para identificar un tipo de música popular cuyos autores, intérpretes y personajes de sus letras pertenecen a poblamientos carenciados, históricamente conocidos con la denominación de "villas miserias", de la ciudad de Buenos Aires, Argentina. Este género aparece como reflejo emergente de la decadencia en que estaba inmersa la sociedad argentina a finales del año 2000, narrando las vivencias de los sectores más marginados de la sociedad. Este estilo musical retoma ciertos códigos de lenguaje de estilo directo y crudo con transgresoras letras de canciones que van desde referencias a historias de vida marginal, exclusión social, corrupción política, consumo de drogas y bebidas alcohólicas, delincuencia, apología del delito, violencia callejera, fútbol y odio hacia la policía y la burguesía. Las compañías discográficas dieron gran visibilidad mediática a estas agrupaciones conformadas por músicos provenientes de sectores bajos, algunos residentes en villas del conourbano bonaerense o barrios periféricos, y, ocasionalmente, con alguna incidencia en actos delictivos. En su vestuario prima el uso gorras con visera, ropa deportiva y jeans amplios de marca premium incluyendo zapatillas Nike o Adidas (Cragnolini, 2006). 
Este acercamiento a los contextos de producción y recepción, nos permite delinear ciertos paralelismos entre ambos casos:

- Ocupación de espacios periféricos de una gran ciudad.

- Grupos de escasos recursos o en situación de exclusión social.

- Estilos musicales que comunican una situación de marginalidad social.

- Narrativas particulares que incluyen modismos locales del lenguaje.

- Letras de canciones que evidencian deseo de superación y éxito económico.

- Finalmente ambos grupos poseen ciertas características físicas identificatorias, con frecuencia utilizadas como una forma de nombramiento negativo, como es el caso del color de la piel. En el caso del grupo cultural asociado al Hip Hop, está en su mayoría conformado por personas de origen afroamericano (recordemos el carácter marginal que caracterizó a este grupo durante su proceso de inserción histórica en los Estados Unidos hasta mediados del Siglo XX).

En el caso de la Cumbia Villera, el popular calificativo de "negro" remite al conjunto de rasgos culturales del villero, como sinónimo de su acepción social y término para referirse despectivamente a los nuevos habitantes pobres que pasaron a integrar el paisaje urbano del gran Buenos Aires desde la década del '40. En este imaginario que se sostiene en el tiempo, el color oscuro de piel se fusiona simbólicamente con la imagen del pobre y el término "negro" se usa como sinónimo de "villero" y "cumbiero" en un doble juego de estigma y emblema de la identidad villera (Vila y Semán, 2008).

\section{Fotografía del ídolo: simbología e industria}

Nos detendremos ahora a analizar las características del soporte fotográfico y el rol e importancia de la imagen y las representaciones, en la red de mediaciones entre prácticas culturales y objetos de consumo. En este caso se trata de fotografías de músicos de sexo masculino que encuentran en la industria musical un privilegiado vehiculo de distribución, utilizadas como portadas de álbumes musicales, a las que sumaremos también fotos de posters, recortes de revistas, adhesivos, camisetas y cualquier otro soporte de promoción de los músicos. Por el particular uso que los fanáticos y seguidores de los músicos hacen de ellas, estas imágenes parecieran portar, en algún aspecto, los valores simbólicos asociados al ídolo musical, a modo de transferencia simbólica al soporte físico, convirtiéndola en una especie de foto-talismán o estampa religiosa. Recordemos que para Debord las prácticas y formas del espectáculo son en cierta forma herederas de la religión, en tanto que uno como el otro están basados en ciertos fetichismos. Tanto en la religión como en el espectáculo, un ideal abstracto se materializa y ese fragmento se propone como totalidad; mediante la manipulación de ciertas imágenes y símbolos se impone ese ideal abstracto a su poseedor (Hardmeier, 2009). Es así que estas representaciones, son coleccionadas y apreciadas por el público como si se tratara de un trozo directamente conectado con el retratado: "No es posible adquirir un producto sin llevarse consigo el sistema de valores que lo envuelve, lo etiqueta y es en definitiva el que lo vende" (Ramírez, 1999) ya que no 
es el valor de uso real, sino la promesa del mismo lo que desencadena esta compra (Hasug, 1980). Un fenómeno funcional a una época donde la sociedad se vincula, como nunca antes, a través de las imágenes (la "sociedad del espectáculo" de Debord), donde todo lo que antes se vivía directamente, se aleja ahora en forma de representación por realidad. Esta fascinación por las fotografías de ídolos musicales, parece enmarcarse también en las condiciones culturales de producción y el mundo encantado de las mercancías de Marx. Podemos trasladar entonces a las imágenes el valor simbólico y no sólo la inmediata finalidad de satisfacer una necesidad humana, por el valor que la cultura de mercado atribuye a las mercancías, donde el impulso de posesión de un objeto (imagen) es promovido por un impulso mimético y una búsqueda de identificación con ciertos patrones de vida y valores de las clases más ricas (Samour, 2006). Debord (1974) da un paso más allá en el concepto de fetichismo de la mercancía: el mundo tangible es reemplazado por una selección de imágenes, donde la realidad es trocada en espectáculo a modo de una relación social mediatizada por imágenes.

Así esta práctica de coleccionar y admirar los retratos de músicos muestra ciertos tintes rituales, donde se exacerba el nivel simbólico de la imagen, en tanto signo, y donde la cualidad emulativa de la fotografía se vuelve particularmente activa; así poseer la fotografía funcionaría como sustituto del fotografiado, portadora de sus aspectos físicos, sensuales, valorativos e ideológicos. Es decir que la fotografía del músico de Hip Hop o de Cumbia Villera, no comunicará solamente una imagen icónica de la persona, sino que funcionará como imagen-texto-cultura que contiene parte de un mundo real o posible (Vilches, 1983). Una imagen de hombre con una estética que demuestra éxito social y económico y que la industria discográfica construye como representaciones que conforman ideales de identificación en relación a demandas grupales y sociales vinculadas al ámbito del deseo y a imaginarios imperantes de una época (Cragnolini, 2006). Estos estereotipos visuales de "hombres antes marginales-ahora exitosos" poseen un gran poder de influencia como elementos culturales con una carga valorativa y contenido simbólico (Cersosimo, 1977). Esta imagen, en su circulación masiva, se conformará como un instrumento dinámico para la legitimación de imaginarios sociales, definidos por Koss como matrices de sentido existencial y elementos indispensables en la elaboración de sentidos subjetivos atribuidos al discurso, representaciones globales o ideas-imágenes.

Así la industria cultural y en nuestro caso, la discográfica, construirá la imagen de alguien en forma de representación, con el objeto de provocar asociaciones que sirvan para identificar tal o cual objeto atribuyéndole ciertas cualidades socialmente elaboradas (Joly, 2009); en nuestro caso, el retrato de cantante de Hip Hop de origen marginal, devenido en artista famoso, portador de prendas y joyas que denotan su éxito social y económico.

\section{Imágenes de cuerpos y ropas}

Entonces si la foto de ídolo posee tal valor de transferencia simbólica, nos ocuparemos ahora de identificar mediante qué elementos visuales lo hace. Es decir, qué combinatoria particular reúnen este tipo de fotografías para operar de un modo tan particular. Para ello retomaremos la premisa de que toda imagen icónica es un artefacto social que transmite 
significado (una apariencia que siempre remite a algo más) y se estructura por convenciones, lo que Eco designa como "sentido contextual" y Canclini (1992) define como la "heterogeneidad multitemporal" propia de la cultura visual y los textos sociales contemporáneos.

Teniendo en cuenta que analizaremos retratos de personas, entenderemos al cuerpo en un sentido cultural, como una constelación persona-cuerpo-imagen donde cada vez que aparecen personas en una imagen, se están representando cuerpos que portan un sentido metafórico: se muestran cuerpos pero significan personas que llevan a cabo un juego de roles (Belting, 2007). Si hablamos del cuerpo vestido deberemos sumar el particular funcionamiento del binomio cuerpo-moda y la forma solidaria en la que se codifican estos roles y valores sociales en una imagen; la forma en que la representación cosifica ciertas configuraciones de poder, éxito y ostentación, para el caso del ídolo musical de Hip Hop o Cumbia Villera.

Es en esta instancia donde la indumentaria cobra un papel preponderante, sobre todo como símbolo de estatus social en la medida que la ropa y su combinación crea discursos sobre el cuerpo. El modo de vestir denota una toma de posición, tanto en un sentido de inclusión e identificación a un grupo, como de diferenciación frente a un referente establecido. De esta manera, como artefactos culturales, el vestuario y los diferentes elementos del decorado corporal se convierten en vehículos de expresión y símbolos de identidad (Fernández, 2010). En nuestro caso de análisis, donde los retratos de músicos muestran una indumentaria ostentosa, la tomaremos como dimensión significante de un fenómeno social. Recordemos primero los elementos iconográficos presentes en ambas representaciones:

- Indumentaria maximizada.

- Ropa deportiva.

- Gran visibilidad de los logotipos de las marcas en indumentaria y calzado.

- Joyas de gran tamaño.

Encontramos en estos objetos a la idea de ostentación, presente en la superficie de los materiales y la escala de las prendas y la joyería, funcionando como símbolos de éxito económico y fortaleza física impulsada quizás por el afán de demostrar el éxito por sobre los orígenes marginales de sus portadores. Este catálogo indumentario no solamente incluye prendas deportivas de primeras marcas, con una evidente visibilidad del logotipo de la marca, sino también prácticas originalmente asociadas a la cultura del Hip Hop, como el sagging, consistente en la exhibición de la banda elástica y zonas de la ropa interior como exterior (Blackman, 2009) que si bien podría ser consecuencia del uso de ropa ancha y pantalones caídos (jeans baggy) surgido en las cárceles donde no existían variedad de talles y se prohibía el uso de cintos (Christian, 2007), su aparición en las fotografías que Herb Ritts realizara para Calvin Klein Underwear (1991), con el cantante Marky Mark (luego devenido en actor como Mark Wahlberg) consolidarían la asociación de esta modalidad con la masculinidad viril. Otro elemento que encontramos en su imágenes son los llamativos accesorios de pesada joyería (denominada con el término bling bling, que habría surgido de la onomatopeya jamaiquina del sonido de las joyas y los destellos que producen), como símbolo del enriquecimiento, fama y riqueza. Esta tendencia sería popularizada por 
los seguidores del subgénero gangsta rap, que inspira su vestimenta en la iconografía gángster mediante el uso de pieles, trajes de llamativos colores y texturas, camisas de seda y zapatos de cocodrilo (Wilkinson, 2011).

Estos elementos funcionan como signos de valores convencionalmente asociados al estatus social, la jerarquía y la pertenencia a un grupo selecto y superior. Se trata de un compendio entre indumentaria, imagen y pose, performado como decorado (Lipovestky y Roux, 2004) más allá de su adscripción territorial. Una indumentaria que connota poder, adoptadas bajo el deseo de parecer rico, el gusto de brillar y la búsqueda de la distinción social a través de los signos demostrativos, objetos y superficies que dan testimonio de un estado de riqueza (marcas, texturas brillantes, tamaños maximizados) como manifestaciones del lujo y de espectáculo ostentatorio, donde el artificio y el adorno funcionan como signos visibles destinados a la mirada del otro. Son atributos de la moda en su dimensión cultural más que estética, operando la indumentaria representada en su nivel más simbólico. Un uso de material distintivo e inscripción de los individuos en una escala de estatus junto a la interiorización de normas, valores e imperativos sociales, en forma de signos y el uso del objeto-símbolo (Baudrillard, 1989). En estas imágenes la escenificación del cuerpo vestido con cierta combinatoria indumentaria afirma la lógica del consumidor que adquiere un bien no solamente por sus cualidades funcionales, sino también por su significación, por lo que simboliza y por la serie de valoraciones emotivas que la posesión de ese bien expresa (Veneziani, 2012).

Estas fotografías estarían funcionando entonces como catálogos a diferentes niveles, incluso mediante cualidades particulares y de alto valor simbólico como el color, el tamaño y la textura. En nuestro caso encontramos estos signos plásticos en el color, la forma y la superficie de los materiales de la ropa deportiva, las joyas y el calzado. Una consideración de la textura como un signo plástico como tarea semiótica relativamente nueva, ejercitada por el Grupo U (Joly, 2009).

En el caso de las joyas y los adornos, se sabe por estudios antropológicos que su objetivo es acentuar las atención sobre la propia persona, aumentando su efecto cuanto más costosos y bellos sean, según los cánones de cada cultura y época. La antigua tradición de los títulos de nobleza como signos de jerarquía social, han mutado en objetos de lujo y finalmente en marcas comerciales, funcionando como signo de diferenciación como si de galones militares se tratara, los que sirven como una forma de distinción, identificación y admiración hacia quien lo lleva. Entonces habrá una relación entre tipo y cantidad de galones con los rangos, al mismo modo que el consumo y ostentación pública de objetos y marcas darán cuenta simbólica del éxito de la persona (Veneziani, 2012).

Es decir que en el contexto de producción y recepción (Hip Hop y Cumbia Villera) se manifiesta la situación periférica y el deseo de trascendencia y éxito social, mediante una indumentaria portadora de ciertas cualidades simbólicas asociadas al lujo y la riqueza. Esta particular construcción visual-estética-indumentaria-performativa permite destacar al individuo en el cuerpo público, portador de un síntoma de poder social auténtico, mediante su inclusión en un escenario de jerarquías (Ortega y Gasset, Los escaparates mandan). Veneziani (2012) puntualiza que en el estilo de vida argentino se aplicaría el mecanismo de adquirir objetos como forma de conseguir una buena reputación. En el caso del cuerpo usando vestimentas costosas y atractivas a simple vista, que evidencien un gasto y 
estén a la moda. Este mecanismo se ve incluso en las clases populares donde la importancia de la compra de zapatillas de marcas costosas y el especial interés por la visibilidad del logotipo identificatorio, denotan el prestigio que se obtiene al usar y mostrar tal objeto. Esta evidente aparición en las fotografías del logotipo de reconocidas marcas de ropa deportiva (Adidas, Nike) es identificable como un mecanismo de reconocimiento, donde si bien la posesión de la riqueza confiere honor y constituye una distinción valorativa, el valor comercial de un objeto no comprende solo su costo material de confección, sino su capacidad de aumento de reputación, como signo de superioridad trasferida al individuo en cuestión (Veneziani, 2012).

Entonces más allá de los orígenes territoriales de las imágenes de músicos masculinos del Hip Hop y la Cumbia Villera, se trata de construir lo que Sevilla (2009) denomina "cuerpoimagen", como un montaje de mercancías, formatos disciplinarios, estéticos y dietéticos en un intento por atrapar aquellos indicadores y signos que hacen del cuerpo una corporalidad deseable. Corporalidad que funciona como registro de ciertos imaginarios de clase, raza, moralidad, sofisticación y seducción. Un conglomerado de ciertos patrones estéticos donde los jóvenes encuentran modelos de identificación y pertenencia en donde afirmarse como individuos ya que "El vestuario, la música y el acceso a ciertos objetos emblemáticos constituyen hoy una de las más importantes mediaciones para la construcción identitaria de los jóvenes" (Acosta, 2007).

\section{De la mimesis a lo transcultural}

Llegado a este punto de nuestro análisis, donde comprobamos que la construcción visual masculina de la Cumbia Villera se encuentra ciertamente influenciada por la estética del Hip Hop, reconocemos que tal hipertextualidad surge gracias a la fotografía y su circulación mediática, vinculando escenarios tan lejanos como Buenos Aires y New York. Tomando la imagen como sinónimo de "representación visual" nos toca repetir aquella pregunta inaugural de Barthes: “¿Como les llega el sentido a estas imágenes?” Cómo se construyen estas proposiciones sobre el mundo a partir de los discursos visuales; qué modelos instituyen y cómo logran ser recepcionadas y aceptadas como modelos-reflejos del mundo. Se trata de identificar los distintos tipos de significantes copresentes en el mensaje visual y hacerles corresponder los significantes que evocan por convención o por uso (Joly, 2009). Si en nuestro caso de análisis encontramos apropiaciones indumentarias que superaron su origen geográfico para ser adoptadas por su valor simbólico, para la adscripción del usuario a un grupo de pertenencia socio-cultural superior, estaríamos hablando sobre los tópicos, representaciones universales y arquetipos ligados a ciertos valores, que fueron producidos y recepcionados gracias a las fotografías en circulación.

Ya no estaríamos hablando entonces de objetos reducidos, como prendas de vestir, joyas y calzado, sino de los imaginarios a los que la representación combinatoria de estos objetos convoca; del carácter convencional que los signos icónicos poseen (probado según Eco, por la historia del arte donde los artistas crearon reglas de traducción de los signos icónicos para poder expresar los contenidos de la realidad). Entonces no sería el objeto de la imagen lo que motiva la organización de la expresión, sino el contenido cultural que le 
corresponde a ese objeto. Vilches (1983) acompaña esta postura cuando determina que representar icónicamente es transcribir según convenciones gráficas y propiedades culturales/ convencionales del objeto, por lo que la imagen es comprensible por medio de reglas culturales ya adquiridas y será el observador quien determine que zonas de semejanza del objeto icónico puede actualizar.

Entonces será gracias a la codificación convencional que estas fotografías de músicos ejecutan como signo (de "músico de origen periférico devenido en personaje reconocido y de éxito económico"). Un uso de la cualidad portable y re armable de las representaciones iconograficas, donde el músico argentino re-presentará (volverá a presentar) estos tópicos mediante la imitación iconográfica. Una acción mediada por la fotografía y la indumentaria, con fuertes huellas de puesta en escena que nos recuerdan las proposiciones de Butler (1988) sobre la cualidad preformativa de la construcción identitaria, funcionando como fabricaciones manufacturadas y sostenidas a través de signos corporales. Estas escenas de ritual social, mediante una performance repetida y actualizada, permitirán experimentar el conjunto de significados ya establecidos socialmente en las representaciones visuales/indumentarias, como forma ritualizada de legitimación. La posesión de una imagen de referencia, mediante la compra de productos asociados a grupos superiores o deseables ( $\mathrm{y}$ a sus valores, normas, comportamientos y beneficios sociales) pareciera ser un modo ficcional de pertencer a él. Así el uso de marcas reconocidas, prendas grandes y brillantes, transformarían a estos productos en símbolos de un estatus social deseado (Sedeño Valdellós, 2007) ya que como lo determina Bourdieu (1988), las propiedades corporales pueden funcionar como capital para otorgar a la representación del cuerpo un reconocimiento incondicional. Así esta performance de querer parecerse a alguien de una clase superior (presente en mensaje visual y el discurso indumentario), originalmente presente en la estética del Hip Hop, será actualizada y repetida en la cultura estética de la Cumbia Villera Argentina.

Estas analogías estéticas y simbólicas evidencian tanto desde el modo de enunciación, los significantes visuales y textuales como desde el contenido de sus mensajes, una adscripción del emisor a la exclusión (Cragnolini, 2006), a la vez de su deseo de éxito económico y social evidenciado en su código indumentario ostentoso. Entonces supondremos que la estética de la Cumbia Villera adopta cierta mimesis de las representaciones del Hip Hop, por su nivel simbólico de lujo, éxito económico y negación-superación de lo marginal. Es decir que la adopción de una estética visual, mediante un código indumentario, hecha pública mediante los mensajes visuales en circulación, será practicado en relación a sus cualidades simbólicas (homologadas por su biografía histórica y su cualidad de tópico en el contexto de los imaginarios sociales), de su valor de signo, sin que esta mimesis obligue a la adopción completa de los significados que originalmente estuvieron presentes en su contexto de producción.

\section{Fotografía y circulación global}

Para finalizar, y ya sustentado que la apropiación de cierto código indumentario del Hip Hop estadounidense por parte de la Cumbia Villera argentina, responde a un traslado de valores simbólicos de poder y éxito social mediante los atributos simbólicos de la indu- 
mentaria fotografiada, deberemos entender que tal vinculación se ha logrado gracias a ciertos mecanismos de circulación de los mensajes visuales en el escenario de la globalización cultural. Un fenómeno que se relaciona, por una parte con la interconexión creciente entre todas las culturas y, por otra, con un flujo de signos y símbolos transitando los discursos a escala global. En virtud de este proceso, las acciones cotidianas y las formas de vida de cada uno permiten forman sistemas vinculares con acontecimientos que ocurren en el otro lado del planeta y con formas de vida absolutamente dispares (Samour, 2006). Una práctica donde la imagen forma parte de un "supermercado del estilo", como lo nombra Ted Polhemus, donde la actualidad contemporánea, caracterizada por la diversidad y el eclecticismo, promueve la posibilidad de surfear entre la geografía y la historia para hallar nuevas realidades, surgidas de mestizajes y reciclajes representacionales difíciles de acotar en categorías contables (Fernández, 2010).

Una generación de jóvenes que encuentran en la escenificación visual de la música (en nuestro caso de análisis) un espacio de identificación y diferenciación mas allá de su lugar de origen; una cultura global donde los procesos de construcción identitaria corresponden a imágenes desterritorializadas, no ligadas ya a un espacio antropológico sino a textos, imágenes y gramáticas producidos por la publicidad, la televisión y el cine en un universo de referencias mundializadas (Acosta, 2007).

Así el vínculo significativo entre las identidades juveniles, la imagen y la música, en el contexto de la globalización, operan como una transversalización de los espacios en los que se construyen.

Las representaciones de aislamiento marginal devenido en éxito económico promovido por los mensajes visuales y el código indumentario del Hip Hop, ya no será entonces una modalidad territorial y compacta, sino una práctica cultural moviéndose en múltiples planos que van de lo local a lo global, desafiando las nociones tradicionales de espacio, vinculadas a la idea de un lugar geográficamente delimitado (Reguillo, 2000).

De todas formas, como expresa Acosta (2007), la existencia de una estética transnacional no implica la pérdida de la iconografía ligada a un territorio; por el contrario, lo mundial incentivaría la diferencia y la fusión, como en el caso del uso de camisetas de fútbol en la cultura de la Cumbia Villera en reemplazo de las camisetas de basquetball o chaquetas de baseball estadounidense.

También Samour (2006) advierte que el mero consumo de bienes "desterritorializados" de circulación mundial, no convierte a nadie en partícipe de una cultura global de masas, "como beber Coca-Cola no convierte a un ruso en norteamericano, ni comer sushi convierte a un americano en japonés". Solo provoca hibridaciones estéticas que aparecen como huellas residuales de estos contactos. Es decir que toda apropiación estéticasimbólica promovida por las imágenes, estará contenida en formas propias de recepción, adaptación y resistencia, por lo que hablaríamos ya de una cultura global, sino sólo de una cultura globalizada, en el sentido de la interconexión creciente entre todas las culturas en virtud de las tecnologías de la comunicación (Samour, 2006). 


\section{Conclusión}

Teniendo en cuenta que las imágenes han influido tradicionalmente en las prácticas culturales y sociales, debemos actualizar que el metamensaje de las representaciones en su circulación global, está intensificando los atributos de la imagen, en su nivel simbólico por sobre el icónico, superando límites territoriales y culturales. En su capacidad comunicativa universal la fotografía resulta particularmente un soporte solidario a la dinámica de la globalización, ya que traspasa las barreras territoriales y se comunica de manera directa con los receptores de todo el mundo, promoviendo una estética transnacional construida por una serie de tendencias y modelos culturales conformados por imágenes que circulan a través de los circuitos audiovisuales a escala masiva. En este escenario la imagen ha acrecentado sus cualidades referenciales y emuladoras para irse convirtiendo en protagonista de la creación de tendencias, superando los modelos y experiencias reales y locales. Para los grupos culturales, que en parte se definen por atributos visuales e indumentarios, la fotografía en circulación le permite trasladar de forma sintética a cualquier territorio del planeta, mediante discursos visuales que ponen especialmente de relieve el valor simbólico indumentario como el color, tamaño y textura, que portados por ídolos musicales, se configurarán como un conglomerado de detalles asociados a valores simbólicos, funcionando a modo de catálogo iconográfico, posible de ser reproducido, como si de listas de instrucciones se tratara, por nuevos receptores.

En nuestro caso donde la Cumbia Villera ha adoptado ciertas formas de representación que remiten a la estética del Hip Hop, entendemos que estas imágenes estáticas han funcionado como medios de enlace y bloques conceptuales (transformados en prácticas preformativas y sociales), portables gracias a su circulación mediática. Las similitudes de los contextos de producción y recepción, en relación a su situación periférica y su necesidad de reconocimiento, han permitido a la cultura de la Cumbia Villera, apropiarse de las soluciones estético-simbólicas que el Hip Hop construyera a partir de un repertorio indumentario practicado como signo de poder y reivindicación social y económica. Una operación que combina mimesis, asociación y regionalización, que más allá de las distancias geográficas y las características particulares de cada grupo, funciona como bloque significante, circulando gracias a sus soportes visuales incluidos en una red global de intercambio de información.

Entonces en la actualidad hipercomunicada, una imagen producida por la industria cultural que circula en las redes globales, se volverá altamente referencial y evocativa, capacitada de recrear iconografías y modalidades culturales, traspasando los límites territoriales, donde las identidades visuales de los jóvenes parecieran estarse combinando sin mayores conflictos.

Ante este fenómeno que conglomerado signico de imagen/indumentaria/cultura circulando en redes desterritorializadas, puntualizaremos la advertencia de Samour (2006), donde mas allá que los procesos de producción y circulación de los mensajes sean efectivamente globales, su apropiación adquirirá siempre un sentido localmente contextualizado. Estas representaciones de identidades grupales asociadas a géneros musicales de carácter marginal (frente a la cultura dominante), se conjugan hoy en un nuevo lenguaje, 
en lo que Fernández (2010) llama "el proyecto del cuerpo de los siglos XX y XXI", donde los escurridizos términos que podrían definirlos como contracultura, subcultura o tribu urbana se reducen a simples adjetivos.

\section{Referencias Bibliográficas}

Acosta, C. (Jul- Dic 2007). Un acercamiento a los vídeo clips de hip hop en Medellín . En Anagramas, Vol. 6, No 11: Medellín: Universidad de Medellín. Facultad de Comunicación. Baudrillard, J. (1989). Crítica a la economía política del signo. Siglo XXI: México. Citado en Croci P. y Vitale A. (2011). Los cuerpos dóciles. Hacia un tratado sobre la moda. Buenos Aires: La Marca Editora.

Blackman, C. (2009). 100 años de moda masculina. Barcelona: Blume.

Bourdieu, P. (1988). La distinción. Madrid: Taurus. Citado en Croci P. y Vitale A. (2011) Los cuerpos dóciles. Hacia un tratado sobre la moda. Buenos Aires: La Marca Editora.

Butler, J. (1988). Gender trouble: feminism and subversión of identity. New York: Routledge. Citado en Croci P. y Vitale A. (2011). Los cuerpos dóciles. Hacia un tratado sobre la moda. Buenos Aires: La Marca Editora.

Castellanos, E. (2012). El rol de la cultura hip-hop en la construcción de la identidad afro y la lucha contra el racismo en EEUU en La Hiedra (En Lluita) (25/10/2012) Aragón: AraInfo, Achencia de Noticias d'Aragón.

Cragnolini, A. (2006). Articulaciones entre violencia social, significante sonoro y subjetividad: la cumbia villera en Buenos Aires en TRANS-Revista Transcultural de Música Recuperado el 12/12/12 de http://www.sibetrans.com/trans/a147/articulaciones-entreviolencia-social-significante-sonoro-y-subjetividad-la cumbia-villera-en-buenos-aires Debord, G. (1974). La sociedad del espectáculo. Buenos Aires: Ediciones de la Flor.

Fernández Silva, C. (2010). El vestuario como identidad, del gesto personal al colectivo. $8^{\circ}$ Jornada Académica de Diseño Industrial. Las personas y los diseñadores: Una buena sociedad. La Paz: Universidad Pontificia Bolivariana. Recuperado de http://proyectomedussa. com/el-vestuario-como-identidad-del-gesto-personal-al-colectivo/

Joly, M. (2009). Introducción al análisis de la imagen. Buenos Aires: La Marca Editora.

Lipovestky, G. (1990). El Imperio de lo efímero. Barcelona: Anagrama.

Lipovestky, G. y Roux, E. (2004). De la era de lo sagrado al imperio de las marcas. Barcelona: Anagrama. Citado en Croci P. y Vitale A. (2011) Los cuerpos dóciles. Hacia un tratado sobre la moda. Buenos Aires: La Marca Editora.

Reguillo, R. (2000). El lugar desde los márgenes. músicas e identidades juveniles . En Nómadas (10/2000)13, pp. 40-53. Bogotá: Universidad Central: .Recuperado el 23/12/12 de http://redalyc.uaemex.mx/src/inicio/ArtPdfRed.jsp?iCve=105115264004

Samour, H. (2006). Globalización, cultura e identidad en Teoría y Praxis, 7, pp. 81-14. San Salvador: Ed. Universidad Don Bosco.

Sevilla, A. (2009). Cuerpo, consumo y placer en Revista Razón y Palabra, 69. Proyecto Internet del ITESM. México: Campus Estado de México. 
Veneziani, M. (2012). Moda, economía y sociedad. Buenos Aires: Nobuko.

Vila, P. y Seman, P. (2008). La música y los jóvenes de los sectores populares:más allá de las 'tribus' en Revista Transcultural de Música, 24. Disponible en: http://www.sibetrans.com/ trans/trans12/art01.htm

Vilches, L. (1983). La lectura de la imagen. Barcelona: Paidos Comunicación.

Wilkinson, K. (2011). Vestirse en el hip hop. Recuperado el 05/06/12. Disponible en: http:// www.bershka.me/es/vestirse-en-el-hip-hop-NDY5NTY.html

Summary: While images carry symbols and ideologies and cultural industry has profusely used this emulative and persuasive quality, we turn on the ways in which, within the current context of global communications, representations transcend its territories and cultural origin groups as ever. Through a case analysis we will identify the scope and effects of photography in the spread-appropriation hybridization between distant territorial cultures. The article proposes a review on the particular operation of visual messages in the context of global communications, where its enhanced symbolic level and evocative capacity of cultural prototypes, has become more complex its representation function, to evoke and culturally mean, beyond its qualities and propositions of origin.

Keywords: clothing - Culture - cumbia villera - fashion - globalization - hip hop - iconography - Photography - representation - semiotics - social imaginary territory - visual discourse.

Resumo: Enquanto as imagens portam simbologias e ideologias e que a indústria cultural tem usado profusamente esta qualidade imitativa e persuasiva, o trabalho ocupase nos modos em que, no contexto atual das comunicações globais, as representações transcendem como nunca antes seus territórios e grupos culturais de origem. Mediante um caso de análise se identificarão os alcances e efeitos da fotografia na propagaçãoapropriação-hibridação entre culturas territoriais distantes. Uma revisão sobre o funcionamento particular das mensagens visuais no contexto das comunicações globais, onde seu potenciado nível simbólico e capacidade evocativa de protótipos culturais, tem virado em mais complexas as funções de representar, de evocar e significar culturalmente, além das suas qualidades e proposições de origem.

Palavras chave: cultura - cumbia villera - discurso visual - fotografia - globalização - hip hop - iconografia - imaginário social - indumentária - moda - representação - semiótica - território. 